\title{
11. A new vision of open knowledge systems for sustainability: Opportunities for social scientists
}

\author{
by
}

J. David Tàbara

\begin{abstract}
In the new open knowledge landscape, social scientists have a unique opportunity to take on a more influential role in accelerating global sustainability learning and transformation. Decisions concerning sustainability are not to be made by policymakers or experts alone, but by different knowledge holders organised around context-specific needs and transdisciplinary practices.
\end{abstract}

\section{Introduction}

The process of producing, organising and using knowledge in science, education and policy is often depicted as a matter of "filling gaps" in an imaginary closed container. Experts may pour in their exclusive ideas on what needs to be known until it is full (Figure 11.1). Of course, this is a caricature of how knowledge systems function and the type of objectives they are meant to accomplish. It hardly fits with what people need to tackle today's global societal challenges. The increasing interconnectedness of knowledge, the speed of change, and the complexity of global systems make it difficult to support the view that any single type of knowledge, practice or even learning process alone is sufficient to deal with the major global environmental challenges of today. In addition, local structures are subject to continuous reconfiguration.

A new view is required of how human information and knowledge systems operate, how they should be organised and how they should relate to the functioning of social ecological systems in the organisation of science, education and policy (Figure 11.2). This world view should unveil the contradictions, deficiencies and misconceptions that particular modes of knowing and learning create, and that are not embodied in specific social-ecological contexts and practices. In this regard, we talk about knowledge systems - not simply "knowledge" - because this concept refers to multiple sets of interrelated knowledge components and their interactions which have their own internal boundaries, dynamics and logic, and which are the result of social-ecological processes. 
Figure 11.1. Knowledge from a single type of source poured into a closed container

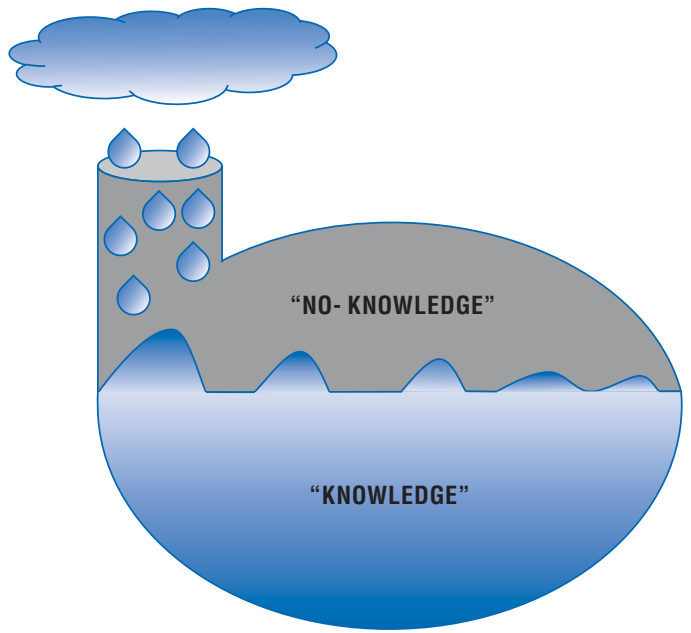

Figure 11.2. Knowledge from many sources, all organised around concrete needs and practices, operating in a social-ecologically coupled open space

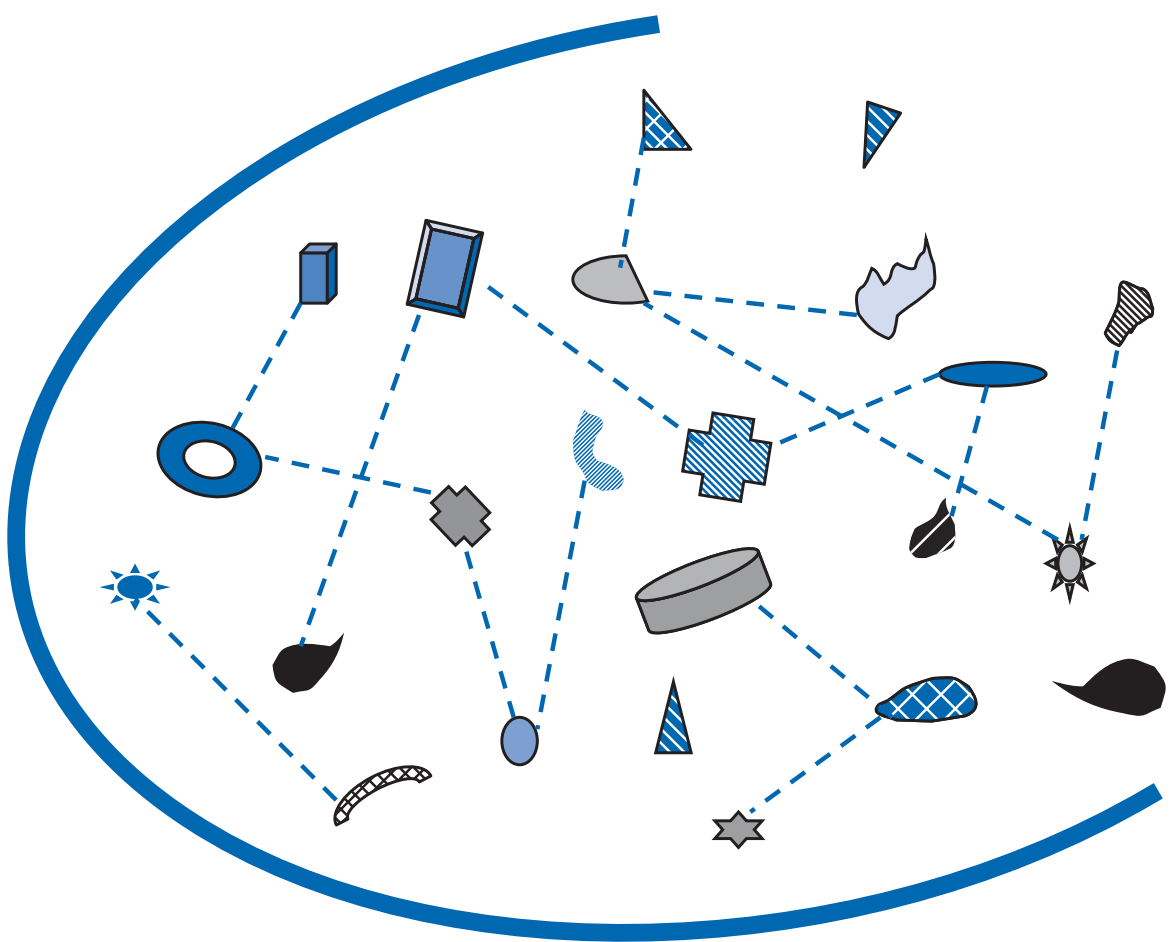

Figure 11.1 depicts knowledge as being constituted from a single type of source poured into a closed container; Figure 11.2 shows knowledge made up from many sources, all organised around concrete needs and practices, operating in a social-ecologically coupled open space.

Encouragingly, this new world view of knowledge systems - an alternative to the view that tries to overcome information and knowledge "deficits" - is trickling down to science planning, education and policy. The Foresight exercise run by the European Science 
Foundation (ESF), "Responses to Environmental and Societal Challenges for our Unstable Earth" (RESCUE; ESF, 2012), synthesised the contributions of approximately 100 experts from 30 countries engaged in developing a transformative vision of science and knowledge practices in the face of global environmental change. The RESCUE vision was built on an open knowledge systems view whereby multiple forms of knowledge are generated from many diverse sources clustered around specific practices and needs. These sources can then be shared among multiple knowledge holders at many levels of action around the world (Cornell et al., 2013). ${ }^{1}$

Many such practices and ways of organising knowledge for sustainability already exist. They range from developing collaborative programmes for climate adaptation in the Andes, to implementing a large-scale project for ecosystem restoration in Niger, to mobilising social expertise and networks of trust in a transition town in the United Kingdom, and to developing new education and research schemes across the globe. ${ }^{2}$ These knowledge-building initiatives are not designed or evaluated by experts alone. Instead they are co-decided, co-produced and co-validated in partnership, by knowledge holders in different social-ecological contexts in which specific needs and demands are to be fulfilled. An important aspect of this vision is that information and knowledge systems operating in an open space must be coupled with social-ecological systems dynamics. This will allow feedback that encourages the modification of behaviours and practices (Tàbara and Chabay, 2013).

This calls for new capacities to deal with social-ecologically situated problems and needs, which usually requires the empowerment of new agents as well as the redistribution of rights and responsibilities. This process is even more central in the open knowledge landscape. This means that criteria and capabilities to deal with "boundary objects" are important in finding innovative ways in which social scientists can help link contextspecific needs with generalisable research outcomes (see Clark et al., 2011). Social scientists could then use such results, and perhaps organise them in the form of theories and models to support sustainability-oriented transformations.

\section{Grounded transformation theory for sustainability}

One of the major contributions social scientists could make from an open knowledge perspective is to develop a solid theory about how to transform global social-ecological systems interactions to meet the sustainability predicament. This could clarify ways to improve the quality of such interactions at various levels and domains of human action; and try to explain the structural constraints and opportunities to doing so. However, such an endeavour cannot be undertaken by one person or discipline alone. A plausible, grounded transformational theory must be built on the civic involvement of many people around the world. They must be committed to contribute to the documentation, classification and analysis of numerous experiences and cases to unravel what works and what does not in terms of changing current arrangements and institutions toward sustainability. ${ }^{3}$

A grounded transformational theory should help us understand how to expand our collective perceptual and cognitive capabilities, and sharpen our moral judgement to deal with the complexities of sustainability transformations. It should enable us to identify the types of incentives, options and resources most conducive to triggering this global transition, and foster the institutional and structural social changes needed to deal with the most urgent challenges. If we place learning at the heart of transformation, recognising 
that we can only transform in the right direction through learning, a transdisciplinary, integrative, open approach that blends insights from theory and practice, and from multiple disciplines and sources of knowledge and expertise, becomes essential.

\section{New opportunities for social scientists, policymakers and funders}

This alternative vision offers a multitude of professional development and innovation opportunities for social scientists. They can play a decisive role in identifying key knowledgeholders relevant to meeting particular needs, and ensuring the sustainable management of a given social-ecological system of reference; and they can contribute to ensuring a fairer distribution of rights and responsibilities in knowledge generation, interpretation, integration and ownership.

The following areas of action may be of interest and relevance to social scientists. Their individual selection of priorities will depend on their own interests, capabilities and institutional commitments.

\section{Methodological innovation}

- Developing new concepts, tools and methods that go beyond simple representation of social-ecological systems dynamics and support their transformation (Tàbara et al., 2010). These new tools could be oriented towards stimulating broad public engagement and creating a sense of ownership of knowledge processes and outcomes, for example by including the arts and other forms of knowledge production and representation.

- Providing robust, integrated methodologies to improve our understanding of the implications of global environmental change and map out what needs to be done in each particular social-ecological situation.

- Designing new criteria for the scientific robustness and validation of sustainabilityoriented research and knowledge building, for example by considering the potential effects of research processes and outcomes on social-ecological systems and on agents' capacities to cope with global environmental change and the challenges of unsustainability.

- Improving our epistemology of the production, collection and integration of knowledge about global environmental change and sustainability, in ways that contribute to global social reflectivity and learning.

- Placing special emphasis on institutional transformation and on innovation processes for sustainability: for example, the most important factors for collective action that allow us to improve our understanding of what needs to be pursued and how societies can "learn what not to do".

\section{Research and education programming and funding}

- Integrating agenda-setting processes in national research plans and programmes with other political agendas, in order to mainstream institutional transformative sustainability.

- Fostering new forms of transnational collaboration in science and education, organised around common needs and practices related to environmental change and sustainability.

- Contributing to diversified research funding sources by encouraging those who use social-ecological research to become more involved in the overall processes of research design, implementation and evaluation. 
- Supporting the development of new research and educational competences and professional careers for young students, so that they can deal with global environmental challenges and sustainability. Career pathways should allow social scientists to work on sustainability, using an open, social-ecologically coupled knowledge systems approach. ${ }^{4}$

- Developing new criteria for scientific excellence and evaluation in research policies. These may not necessarily be incompatible with existing ones, but should be extended and reframed following a reflective process in which context-based processes, goals and capacities to deal with sustainability and institutional transformation are introduced.

\section{Cultural and societal transformation}

- Carrying out participatory processes to explore place-based transformation pathways that go beyond partial solutions that create greater systemic problems; encouraging reflection on the systemic effects of technological innovation before technologies and processes are implemented, to prevent unsustainable path dependencies.

- Supporting the formation of learning networks of action that can show the value of transformative sustainability research, while encouraging new agents to become involved and participate in these networks; enhancing the reflexivity and transformational potential of learning networks based on information and communication technologies used in science, education and policy.

- Supporting reframing processes concerning societal goal-setting and collective sensemaking. This can be done by embedding knowledge production processes within concrete social-ecological contexts of action in which stakeholders' needs and perspectives have been identified and taken into account.

- Counterbalancing existing power structures and inequalities, as inequality is a major driver of unsustainability. This could be done by supporting the redistribution of institutional rights and responsibilities derived from new forms of coupled knowledge production and use. Attention ought also to be drawn to oppressed groups, such as women, ethnic minorities and young people, and giving them the opportunity to speak out.

- Developing and implementing economic and social incentives to support sustainability. Here conflict situations may be reframed and turned into win-win, systemic and sustainability-oriented strategies, perhaps linking climate change mitigation, adaptation and sustainable development.

- Helping contemporary societies to extend our perceptual, cognitive and moral systems of reference to include the rights of future generations, and promote respect for the value of non-human forms of life. These should be considered from a global perspective and in a relational way, in order to overcome many of the false modern dualisms that hinder sustainability learning (Tàbara and Pahl-Wostl, 2007). ${ }^{5}$

\section{Concluding remarks}

Humankind is now engaged on a "learning race" against the speed and intensity of global environmental change. Social scientists have unique opportunities to play an increasingly decisive role in accelerating learning and transformation directed towards global sustainability. In the new open knowledge landscape, the rules of engagement between scientists, policymakers and citizens are likely to be transformed. We can envisage radically new forms of collaboration between social scientists in transdisciplinary teams 
and communities. Social scientists have to take part increasingly in decisions about new networks of action for sustainability, in repositioning research in this open and ecologically embodied knowledge space, and in sharing and upscaling local successful experiences. These experiences could be communicated and made visible in communities around the world, which in turn could share and improve such knowledge to speed up sustainability transformations. The new situation demands internal changes within the social science disciplines. It will involve new mind-sets, new practices and new professional norms, new institutional incentives, and imaginative ways of rethinking the validity and the quality in social-ecological interactions. ${ }^{6}$

This daunting task requires fresh theoretical and methodological perspectives on knowledge systems. But above all, it calls for specific policies, resources and measures designed to transform the existing interactions between knowledge production and sustainability-oriented actions. A new vision of open but social-ecologically coupled knowledge systems could help us appreciate the value of local knowledge and experience that is crucial for sustainability. It might also help us abandon the idea that one single kind of knowledge fits us all. Multiple and novel ways of learning, knowing and sharing science, education and policy-making responsibly are urgently required, as are new forms of civic engagement; and they are also attainable, in this increasingly complex but morally challenging world.

\section{Notes}

1. See the EU project VISIONRD4SD www.visionrd4sd.eu and the Future Earth initiative www.icsu. org/future-earth. Here, I regard knowledge holders as people who actually have the expertise to contribute positively to and deal with a given problem, or to meet a given need in a particular social-ecological context.

2. See, for instance, the Niger case, www.ecologyandsociety.org/vol16/iss3/art1/main.html; with regard to the transition towns: www.transitionnetwork.org; and for sustainability innovation in education, see the Barefoot College: www.barefootcollege.org and also the CEMUS centre at Uppsala University: www.csduppsala.uu.se.

3. Elinor Ostrom's efforts to examine the conditions for the sustainable governance of common pool resources are perhaps the best example of such approaches that link empirical evidence with sustainability theory (see Ostrom, 2009).

4. This could benefit from collaborative learning processes involving problems and projects combined with visioning and modelling techniques and other models of systems learning.

5. Among these cultural dualisms are those related to our contemporary concepts and values about time and space as well as our basic ideas about what constitute social-ecological system processes. Dichotomies between human and non-human information systems, interactions and structures are instances of these; for example, we are in nature as much as nature is in all of us.

6. In this regard, the emergence of "global systems science" could make this possible, with the extensive use of participatory information and communication tools www.gsdp.eu and http://blog. global-systems-science.eu.

\section{Bibliography}

Clark, W. C. et al. (2011), "Boundary work for sustainable development: Natural resource management at the Consultative Group on International Agricultural Research (CGIAR)", Proceedings of the National Academy of Sciences, doi: 10.1073/pnas.0900231108, www.pnas.org/content/ early/2011/08/11/0900231108.abstract. 
Cornell, S. et al. (2013), "Opening up knowledge systems for better responses to global environmental change", Environmental Science and Policy, Vol. 28, pp. 60-70, www.sciencedirect.com/science/article/pii/ S1462901112002110.

ESF (2012), Responses to Environmental and Societal Challenges for our Unstable Earth (RESCUE), ESF Forward Look - ESF-COST "Frontier of Science" joint initiative, European Science Foundation, Strasbourg and European Cooperation in Science and Technology, Brussels, www.esf.org/publications/forwardlooks.html.

Ostrom, E. (2009), "A general framework for analyzing sustainability of social-ecological systems", Science, Vol. 324/5939, pp. 419-422, www.ncbi.nlm.nih.gov/pubmed/19628857.

Tàbara, J. D. and I. Chabay (2013), "Coupling human information and knowledge systems with social-ecological systems change. Reframing research, education and policy for sustainability", Environmental Science and Policy, Vol. 28, pp. 71-81, www.sciencedirect.com/science/journal/14629011/28.

Tàbara, J. D. and C. Pahl-Wostl (2007), "Sustainability learning in natural resource use and management", Ecology and Society, Vol. 12 /2, p. 3, www.ecologyandsociety.org/viewissue.php?sf=28.

Tàbara, J. D. et al. (2010), "The climate learning ladder: A pragmatic procedure to support climate adaptation", Environmental Policy and Governance, Vol. 2/1, pp.1-11, http://onlinelibrary.wiley.com/ doi/10.1002/eet.530/abstract.

J. David Tàbara is a member of the Global Climate Forum and associate researcher the Institute of Environmental Sciences and Technology, Autonomous University of Barcelona. He works on socio-environmental sciences and integrative environmental methods, focusing on social learning, communication and public participation for sustainability. 